\title{
FEDERALISMO E RELAÇÕES INTERGOVERNAMENTAIS: IMPLICAÇÕES PARA A REFORMA DA EDUCAÇÃO NO BRASIL
}

\author{
Valeriano Mendes Ferreira Costa*
}

\begin{abstract}
RESUMO: $\mathrm{O}$ artigo argumenta que o federalismo brasileiro apresenta uma dinâmica institucional favorável à construção de um Sistema Nacional de Educação, não necessariamente sob o controle centralizador do governo federal. Primeiro, introduzo algumas observações sobre uma distinção de natureza conceitual entre federalismo e Federação. Depois, argumento que o modelo original de federalismo construído pelos Estados Unidos foi arranjo institucional concebido especificamente para tornar possível a construção de um Estado nacional. A seguir, procuro demonstrar que o federalismo foi utilizado pelas elites políticas brasileiras como um arranjo que permitiu formar Estados nacionais a partir de governos regionais oligárquicos. Discuto, por fim, o novo sentido que o federalismo vem adquirindo atualmente para a construção das políticas públicas no Brasil.
\end{abstract}

Palavras-chave: Federalismo. Relações intergovernamentais. Políticas públicas. Políticas educacionais.

FEDERALISM AND INTERGOVERNMENTAL RELATIONS: IMPLICATIONS FOR THE EDUCATION REFORM IN BRAZIL

ABSTRACT: This paper argues that the institutional dynamics of Brazilian federalism is favorable to the construction of a National Education System, not necessarily under the Federal Government's centralized control. After a few remarks on the conceptual nature of the distinction between federalism and federation, it advocates that the original model of U.S. federalism was an institutional arrangement specifically aimed at allowing the construction of a

Doutor em Sociologia e professor-assistente do Instituto de Filosofia e Ciências Humanas da Universidade Estadual de Campinas (UnICAmP).E-mail: vmfc@unicamp.br 
Federalismo e relações intergovernamentais...

national state. It then shows that federalism was used by the Brazilian national political elites as an arrangement to favor the emergence of National States based on oligarchic regional elites. Finally, it discusses the new direction federalism is currently taking in Brazil as for the construction of public policies in Brazil.

Key words: Federalism. Intergovernmental relations. Public policies. Educational policies.

A

ntes de analisar a construção do Estado federativo no Brasil, introduzo algumas observações sobre uma distinção de natureza conceitual importante, que ajuda a identificar as causas da nossa dificuldade em integrar num mesmo projeto político a luta pela construção de um Estado nacional moderno e democrático e a organização de uma estrutura federativa, flexível, pluralista e cooperativa.

Ainda que se encontrem bastante entrelaçados historicamente, federalismo e Federação referem-se a dois fenômenos bastante diversos. Quando dizemos Federação, estamos nos referindo a um Estado organizado constitucionalmente sob um regime federativo, isto é, que reconhece duas ou mais esferas de poder político - com graus diferenciados de autonomia - dentro de um mesmo espaço territorial cujo monopólio da coerção legítima, e portanto a soberania, é exercido por um único corpo político: o governo federal. Quando usamos a palavra federalismo, estamos fazendo referência a um princípio de organização política tão complexo e relevante para a compreensão do mundo contemporâneo como o liberalismo, o socialismo ou o comunismo (King, 1982). Em geral, encontramos três tipos de ideologia federalista associados às experiências de implantação de federações: 1) as de orientação centralizadora, como no caso norte-americano; 2) as de orientação descentralizadora, como no caso brasileiro, e; 3) as que propóem um balanço entre centralização e descentralização, como é o caso da Alemanha ocidental após a Segunda Guerra Mundial.

Essa distinção preliminar entre Federação e federalismo é indispensável para qualquer análise comparativa de estados federados ou mesmo para a avaliação do funcionamento do sistema federativo em um único estado. E a razão é simples de entender: existem muitos estados organizados constitucionalmente como federaçóes, mas o funcionamento real dos sistemas federativos apresenta enormes variações no tempo e 
no espaço. Isto é, os princípios políticos que regem ou fundamentam cada Federação são flexíveis e dinâmicos. Varia não apenas o grau de autonomia dos governos subnacionais em relação ao governo federal, mas também os mecanismos institucionais (formais ou informais) que condicionam as relações entre os entes associados, tanto no que diz respeito aos aspectos competitivos como cooperativos.

Mais do que uma camisa de força normativa, o conceito de federalismo funciona como uma ideia reguladora, uns "horizontes" normativos, em relação ao quais as federações e mesmo Estados constitucionalmente unitários - como a Itália, a França, a Espanha, na Europa, e o Chile e a Bolívia, na América Latina - confrontam e comparam seus sistemas político-administrativos, orientando tanto reformas constitucionais amplas como a criação de mecanismos formais ou informais que aperfeiçoam os processos decisórios compartilhados por unidades políticas ou administrativas com maior ou menor grau de autonomia. E quais são os princípios fundamentais da "ideologia" federalista? Embora existam naturalmente divergências entre os estudiosos, é possível resumir os elementos básicos do federalismo.

1) o princípio contratual ou associativo: segundo o qual todo o poder legítimo só pode ser resultado de pactos, convenções, associações ou contratos entre indivíduos ou comunidades (políticas) autônomas. Obviamente, essas comunidades (e indivíduos) são livres para se associar de forma mais ou menos permanente, em função de objetivos de maior ou menor alcance e complexidade;

2) o princípio do pluralismo político: segundo o qual a existência de duas ou mais comunidades políticas autônomas (mas não soberanas) dentro de um mesmo estado constitui uma maior garantia para a liberdade e, portanto, para a busca da igualdade principalmente em sociedades de grandes dimensóes territoriais e populacionais, marcadas por heterogeneidade cultural e social e consideráveis desigualdades econômicas, característica predominante nos Estados contemporâneos;

3) o princípio da subsidiariedade: segundo o qual a responsabilidade pelas decisóes e ações coletivas dentro de uma comunidade política pertence a todos os que serão (potencialmente) afetados por elas, tanto positiva como negativamente. Assim, todas as comunidades territoriais - um bairro, um município, uma região 
Federalismo e relações intergovernamentais...

ou um estado - e setores da sociedade civil terão prioridade na definição da legislação e/ou na implementação de políticas públicas que afetem exclusivamente essas comunidades, respeitados os limites de sua capacidade fiscal e administrativa. Nos casos de dificuldade de financiamento e/ou execução dessas políticas, os demais entes federativos, principalmente estados e União, deverão colaborar para que essas comunidades alcancem as condiçõos necessárias e suficientes para realizar esses objetivos;

4) o princípio de equidade federativa: segundo o qual todos os membros federados têm direito, na medida em que cumpram seus deveres, a todo auxílio necessário para garantir padrões mínimos de existência às suas comunidades e aos indivíduos que nelas habitam.

Integrados num único corpo doutrinário, esses princípios procuram garantir, dentro das limitações inerentes a uma comunidade política real, a compatibilização dos princípios básicos do governo democrático: liberdade, igualdade e eficácia (Stepan, 1999). Sob esses princípios muito gerais que são, como já observei, horizontes normativos, desenvolveram-se experiências concretas de federalismo que tornam extremamente complexa uma análise comparada. $\mathrm{O}$ que se pode afirmar, com relativa certeza, é que onde o experimento federalista se mostrou mais bem-sucedido verificou-se uma tendência de convergência ou equilíbrio entre liberdade - expressa pelos princípios do contratualismo e do pluralismo territorial - e igualdade - consubstanciada nos conceitos de subsidiariedade e equidade -, garantido por instituições que deram maior eficácia à dinâmica das relações intergovernamentais. Neste sentido, uma tendência comum a todos os estados federativos é o desenvolvimento de mecanismos (verticais e horizontais) de redistribuiçãao de poder e de recursos fiscais entre os governos subnacionais.

O resultado desse processo é duplo, pois simultaneamente tende a fortalecer a capacidade de intervenção do governo federal - por intermédio dos mecanismos de transferência de recursos fiscais (equalização) e da definição de regras e pisos básicos de quantidade e qualidade das políticas públicas mais importantes - assim como acaba por ampliar e intensificar o campo das relaçôes intergovernamentais, fortalecendo igualmente o papel dos governos regionais e locais. 
Mas esta é uma definição ainda bastante geral do processo federativo, pois não permite comparar e diferenciar com precisão as variantes de federalismo, especialmente de uma perspectiva política institucional. Neste sentido, o federalismo diferencia-se claramente dos sistemas unitários, na medida em que se baseia em dois princípios de representação e, portanto, de legitimação: a representação popular propriamente dita, que abrange todos os cidadãos aptos a votar e constituir governos, e a representação territorial, que atribui a cada governo subnacional direito de constituir representantes (eleitos ou nomeados) junto do poder nacional, limitando a esfera de ação da representação popular. Os regimes federativos, desta perspectiva, caracterizam-se pelo maior ou menor equilíbrio político-constitucional entre os poderes da Uniāo (Executivo, Legislativo bicameral e Judiciário) e os poderes dos governos subnacionais. De acordo com Stepan (1999), seriam quatro as variáveis mais relevantes para se caracterizar o tipo de federalismo vigente em cada país:

1) Grau de sobrerrepresentação da Câmara territorial (Senado): quanto maior é o grau de sobrerrepresentação dos Estados menos populosos (e maior, portanto, a sub-representação dos Estados mais populosos), maior é a probabilidade de que o Senado represente interesses regionais ou locais em detrimento dos interesses da maioria da população do país.

2) Escopo das competências políticas atribuídas pela Constituição ao Senado: quanto maiores as competências para legislar concorrentemente com a Câmara, maior a capacidade do Senado de limitar a prevalência dos interesses majoritários em âmbito nacional.

3) Número de competências legislativas atribuídas pela Constituição aos estados-membros: quanto mais competências legislativas forem atribuídas às unidades subnacionais pela Constituição, menor será o escopo de atuação do governo central e, portanto, maior a predominância dos interesses regionais e locais no sistema político em questão.

4) Grau de nacionalização do sistema partidário: quanto maior o controle das direçóes partidárias sobre os representantes e governantes eleitos, maior a orientação das forças políticas favoravelmente aos interesses organizados em âmbito nacional. 
Federalismo e relações intergovernamentais...

Como se pode perceber, cada uma das variáveis produz efeitos no sentido de maior ou menor grau de controle do processo decisório por interesses organizados em âmbito nacional ou regional/local. De um lado, quanto menos desproporcional a representação no Senado, quanto menores suas competências constitucionais, menor o âmbito de autonomia legislativa dos estados-membros e maior o controle das direções nacionais dos partidos sobre os representantes, maior a sensibilidade do poder político aos interesses nacionais. De outro, quanto mais desproporcional e quanto mais atribuições legislativas detêm o Senado, quanto mais extensas as competências legislativas dos estados-membros e menor o controle das direções nacionais sobre a seleção e a ação política dos representantes eleitos, menor o controle do governo central sobre o processo decisório. Num extremo teríamos os tipos de federalismo mais "nacionalizados" - como o alemão, o canadense, o australiano e o indiano. No outro, teríamos os sistemas federativos mais descentralizados, como o norte-americano e o brasileiro.

Além dessas variáveis, poderíamos acrescentar outras que contribuem para caracterizar o grau de centralização ou descentralização dos sistemas federativos. Por exemplo, quanto maior o número de partidos atuando no âmbito federal, maior ou menor o espaço para a representação de interesses estaduais e municipais. Isso porque, quanto mais partidos efetivos no âmbito federal, maior a chance de que essas organizações políticas tenham bases eleitorais concentradas em alguns estados ou numa região determinada do país.

Nestes casos, o elemento condicionante é o caráter mais ou menos restritivo do sistema eleitoral. Quanto mais o sistema eleitoral se aproxima do modelo majoritário, isto é, distrital uninominal (um deputado eleito por cada distrito), desde que o processo de seleção dos candidatos seja atribuição dos dirigentes nacionais, é forte a tendência para a configuração de um sistema bipartidário e, portanto, maior a probabilidade de gravitação dos partidos em torno dos interesses de âmbito nacional. No sentido contrário, atuam os sistemas de tipo proporcional, desde que o controle das indicações não esteja nas mãos das direções partidárias nacionais (sistema de lista fechada).

É neste quadro conceitual e histórico que adquire sentido uma breve referência à experiência pioneira do federalismo norte-americano. 
É amplamente reconhecido que o federalismo, como uma forma de organização política compatível com o Estado moderno, foi inventado pela elite política norte-americana no século XVIII. Antes de 1787, não se concebia um Estado soberano que não fosse unitário, isto é, governado pela vontade de um único sujeito político. Todas as experiências de Estados compósitos, isto é, formados por mais de um governo soberano, se reduziam às instáveis confederaçōes, geralmente constituídas com objetivos bastante específicos (como a defesa de cidades-Estado contra o expansionismo de impérios, ou a expansão comercial de pequenas repúblicas). A própria experiência confederativa norte-americana de 1776-1787 demonstrou a fragilidade desse tipo de arranjo.

A genialidade dos legisladores norte-americanos foi conceber um sistema político fundado sobre um Estado soberano, mas não unitário. A partir da Constituição de 1787 , os três poderes da União passaram a concentrar a capacidade de decisão soberana, isto é, irrecorrível, sobre as competências essenciais à existência de um Estado moderno: a política externa (principalmente a guerra), o comércio exterior, mas, principalmente, a arrecadação de impostos e a administração da justiça em assuntos de interesse nacional. Os estados mantiveram a soberania sobre as competências residuais, pelo menos enquanto estas não conflitassem com os interesses nacionais.

O federalismo permitiu que a democracia norte-americana seguisse uma trajetória bastante complexa: na esfera federal assistiu-se à consolidação de um sistema político competitivo e crescentemente nacionalizado, nos estados industrializados do norte surgiram regimes competitivos com alta capacidade de incorporação das minorias étnicas, acompanhados por políticas sociais inclusivas; os estados do sul, ainda fortemente dependentes da mão de obra escrava, mantinham regimes eleitorais restritivos e políticas sociais discriminatórias.

Em síntese, o federalismo foi concebido como uma fórmula que permitia compatibilizar os interesses das elites nacionais modernizadoras com os diferentes projetos políticos das elites regionais. No limite podemos concluir que o federalismo teve um efeito restritivo, ou moderador, sobre o ritmo e a intensidade de formação de um regime democrático de massas nos Estados Unidos.

Quando os primeiros Estados nacionais começaram a se formar na América Latina, a experiência federativa norte-americana ainda era 
Federalismo e relações intergovernamentais...

bastante recente. Este foi o modelo político que exerceu maior influência ideológica do federalismo sobre as elites latino-americanas.

O que se pode afirmar, com relativa certeza, é que, onde as experiências de adaptação do arranjo federalista se mostraram mais bemsucedidas (Canadá, Austrália, Alemanha, Suíça), o padrão de construção político-institucional e administrativo alcançou um alto grau de complexidade no âmbito das relaçôes intergovernamentais, isto é, formaram-se verdadeiras redes que articularam os diversos níveis de governo (no sentido vertical) assim como as unidades subnacionais (governos, províncias, regiōes e comunidades locais) e as mais diversas associaçóes da sociedade civil e de empresas. Esses sistemas reticulares são responsáveis por um amplo escopo de decisões e ações no campo das políticas públicas que não são responsabilidade exclusiva de um dos níveis de governo.

É interessante observar que esse padrão de decisões compartilhadas por complexas redes intergovernamentais e sociais (que estão concentradas na área de atuação dos poderes executivos, mas tendem a se estender aos demais poderes - Legislativo e Judiciário) alcança cada vez mais países de tradição fortemente unitária (como Grã-Bretanha, França e Itália), bastante influenciados, é certo, pela experiência de construção da União Europeia. O resultado de tudo isso, afinal, aponta para um "transbordamento" dos princípios de organização federativa para a arena internacional, o que torna ainda mais interessante o estudo das potencialidades do federalismo como forma de governo.

$\mathrm{O}$ que pretendo mostrar a seguir é que o padrão de desenvolvimento institucional do nosso federalismo apresentou traços de "subdesenvolvimento" quando comparado com experiências internacionais bem-sucedidas. E apenas muito recentemente, a partir do processo de descentralização fiscal, política e administrativa que assistimos desde o início da década de 1980, iniciamos a construção de um Estado nacional, democrático e federativo.

Esta afirmação de certo modo polêmica decorre da argumentação anterior pela qual procurei distinguir o conceito de federalismo das federações realmente existentes. Deste ponto de vista, a Federação brasileira mostra distância com relação ao processo de "adensamento das redes de relações intergovernamentais” verificado no âmbito internacional.

Uma observação preliminar com respeito aos fundamentos políticos do Estado federativo brasileiro é que ele se mostrou "prisioneiro", 
desde a proclamação da República em 1889, de um movimento pendular entre processos de centralização autoritária e processos de descentralização descoordenada e em muitos casos "predatória" (cf. Abrucio \& Costa, 1998). Por trás do intenso processo de crescimento econômico, demográfico e social que marcou a nossa história republicana, encontramos um sistema político e administrativo formalmente federativo, mas fortemente caracterizado por um processo decisório fragmentado, descoordenado e muito pouco "republicano" (Abranches, 1988).

É possível afirmar, portanto, que, em nossa trajetória de construção do Estado moderno, o federalismo não esteve, inicialmente, associado nem ao desenvolvimento econômico nem à implantação da democracia.

Ao contrário, as diversas tentativas de descentralização política desde o Império - Ato Adicional (1834-1840), Primeira República (1889-1930), Segunda República (1946-1964) - fracassaram politicamente, redundando em movimentos de recentralização e/ou autoritarismo. Mas, antes de retomar mais uma vez a velha tese dos ciclos de sístole/diástole de Golbery, é preciso deixar claro que o aparente dilema pode ser mais bem entendido como uma tensão estrutural entre dois processos históricos simultâneos: desenvolver e consolidar simultaneamente o Estado nacional e o regime democrático.

Para se avaliar as implicações desse fato, é importante ter em mente que, ao longo da história moderna e contemporânea, a maioria dos países que hoje consideramos desenvolvidos - e entre estes se encontram a maioria dos Estados federativos -, a construção do Estado nacional e o desenvolvimento do regime democrático representativo foram processos que levaram décadas e mesmo séculos e, mais importante, em regra geral não foram processos simultâneos. A história dos países ocidentais mais bem-sucedidos mostra que o processo de construção e consolidação do Estado nacional foi um pressuposto para o desenvolvimento de regimes políticos, primeiro representativos e, somente depois, plenamente democráticos.

É preciso ter claro as dificuldades envolvidas na construção simultânea de um Estado forte e moderno - o que impôs historicamente um considerável grau de centralização e concentração de poder coercitivo e autoridade política nas mãos do governo federal - e de um 
Federalismo e relações intergovernamentais...

regime político representativo e democrático, num contexto internacional extremamente dinâmico e bastante desfavorável à preservação de autonomia política e econômica por parte das nações "emergentes". Quando a este cenário acrescentamos a questão federativa, os problemas multiplicam-se na mesma dimensão das regióes e dos estados que compóem o imenso e desigual território brasileiro.

Por sua própria natureza institucional, o federalismo desenvolveu-se historicamente como uma solução política para a construção de um Estado nacional em uma sociedade bastante avançada à época no desenvolvimento do regime representativo, e mais adiante democrático: os Estados Unidos da América. O sentido político do federalismo norte-americano deve ser ressaltado não para que nos comparemos negativamente com ele, mas justamente para que saibamos diferenciar claramente a natureza distinta da experiência federativa no Brasil, embora haja também semelhanças e saibamos aprender com determinados instrumentos do federalismo norte-americano.

Ao contrário dos países latino-americanos, o federalismo norteamericano resultou num arranjo político em que comunidades com alto grau de autonomia e liberdade políticas resolvem construir um governo relativamente fraco para coordenar algumas funçóes, enumeradas constitucionalmente, que essas comunidades se consideravam incapazes de cumprir com a eficácia necessária - defesa externa, emissão e controle da moeda, política externa etc. Ora, quais eram nossos problemas, quando optamos pela República Federativa em 1889?

Transformar um imenso e desarticulado território, dominado por oligarquias regionais, cujo impulso isolacionista - e não o desejo de autonomia - fora sufocado durante mais de 40 anos pelo regime monárquico centralizador, numa nação minimamente integrada econômica e politicamente sob os fundamentos de um regime fragilmente representativo. Mas, ao contrário da experiência norte-americana, o impulso democratizante não estava nos governos locais, e sim numa pequena parcela das elites nacionais - representadas por figuras como Tavares Bastos, Joaquim Nabuco e Rui Barbosa -, que se contrapunham à outra parte das elites nacionais que consideravam impossível desenvolver um Estado nacional forte e modernizador delegando poderes substantivos às elites regionais - representavam a corrente "autoritária” e centralizadora homens como o Visconde de Uruguai, Alberto 
Torres e Oliveira Viana. Toda a nossa história republicana se resume na dificuldade de nossas elites políticas em resolver o conflito aparentemente inconciliável entre a construção de um Estado nacional forte e modernizante e a consolidação do regime representativo e democrático. É compreensível que ao longo desse processo, o experimento federalista tenha sido sufocado, deformado e fartamente manipulado pelas elites políticas, seja atribuindo-lhe a responsabilidade pelo caráter privatista e autoritário dos governos estaduais e municipais, seja tomando-o como panaceia para todos os males da centralização.

A historiografia brasileira tem interpretado esse processo como um eterno ciclo de centralização autoritária e descentralização predatória (Abrucio, 2002). As interpretaçôes contemporâneas enfatizam duas variáveis cruciais para entender a dinâmica basicamente centralizadora das relações intergovernamentais no Brasil: a capacidade da Presidência da República de exercer forte controle sobre o Congresso (Limongi \& Figueiredo, 1998) e o maior ou menor controle do governo federal sobre a distribuição e o uso de um volume considerável de recursos fiscais (Arretche, 2000). Nesta breve discussão do caso brasileiro, argumento que as condições para a centralização do poder nas mãos do governo federal realmente dependeram, e ainda dependem, da capacidade política e institucional da Presidência da República de assegurar o controle sobre essas duas variáveis centrais. No entanto, como procuro demonstrar, essas condições variaram bastante. Embora não concorde que a dinâmica institucional do federalismo no Brasil possa ser compreendida como um eterno ciclo de centralizações e descentralizaçôes, as características estruturais da Federação brasileira, especialmente quando analisadas de uma perspectiva comparada, apontam para uma considerável instabilidade endógena ao sistema. Finalmente, argumento que essa instabilidade crônica da Federação brasileira tem impacto sobre a dinâmica da cooperação intergovernamental tanto vertical como horizontal.

A dinâmica institucional das relações intergovernamentais no Brasil pode ser mais bem entendida tendo como pano de fundo algumas características históricas da formação do Estado federado em 1889. Contemporâneo de outras federaçôes como a canadense (1867) e a australiana, o federalismo brasileiro nasceu associado ao peculiar republicanismo das elites provinciais (depois estaduais), e resultou no que se pode denominar de "federalismo oligárquico". 
Federalismo e relações intergovernamentais...

A característica principal dessa primeira fase do federalismo brasileiro foi a grande autonomia fiscal dos estados, dominados por elites latifundiárias sustentadas pela exportação de produtos agrícolas. O equilíbrio político da Federação dependia de um jogo complexo de coalizões entre os estados mais poderosos, como São Paulo, Minas Gerais e Rio Grande do Sul, que lutavam pelo controle do governo federal, e os estados intermediários, como Rio de Janeiro, Bahia e Pernambuco.

Ao longo do século Xx, o federalismo brasileiro e suas relações intergovernamentais foram marcados por dois processos simultâneos. O primeiro foi o crescimento da força política e econômica do governo federal, especialmente perante os estados mais poderosos. $\mathrm{O}$ segundo foi o desenvolvimento de um sistema partidário competitivo em âmbito nacional a partir de 1946. Desse modo, os grandes estados perderam a capacidade de controlar diretamente o governo federal por meio de alianças, embora tenham conservado a capacidade de influenciar na definição dos rumos da política nacional (Abrucio, 2002).

A persistência do "federalismo estadualista" (Abrucio, 2002) entre os anos de 1960 e 1990 pode ser comprovada pela participação decisiva dos governadores dos estados mais importantes em conjunturas críticas, como a resistência do governador do estado do Rio Grande do Sul à tentativa de golpe militar em 1961, o apoio decisivo ao golpe militar de 1964, assim como o apoio político estratégico ao movimento de redemocratização a partir de 1982 (Costa, 2005). Em todos esses momentos, os governadores demonstraram capacidade de influenciar decisivamente nos rumos políticos do país.

Entre 1985 e 1995, os governos estaduais alcançaram força ainda maior ante um presidente escolhido por um colégio eleitoral vinculado ao regime militar. A crescente predominância dos interesses dos governos estaduais e municipais culminou na Assembleia Nacional Constituinte (1987-1988), que consolidou o processo de descentralização política e fiscal iniciado em fins dos anos de 1970 (Abrucio, 2002).

Entretanto, o governo nos estados e municípios caracterizou-se pela excessiva concentração de poder nas mãos de governadores e prefeitos (Abrucio, 2002). O baixo grau de accountability e a crescente irresponsabilidade fiscal dos governos subnacionais resultaram numa crise financeira sem precedentes, com efeitos na política macroeconômica nacional e nas políticas sociais. Desse modo, constituiu-se um federalismo 
estadualista e predatório, cujos impactos negativos se manifestaram na fragilidade das máquinas públicas estaduais e num endividamento subnacional que ultrapassou a casa dos 100 bilhôes de dólares em fins da década de 1990 (Abrucio \& Costa, 1998).

A grande inflexão neste processo de descentralização predatória ocorreu a partir da Presidência de Fernando Henrique Cardoso. Liderando uma ampla e heterogênea coalizão de partidos de centro e direita, Fernando Henrique Cardoso foi capaz de restringir fortemente os recursos fiscais e políticos dos governos estaduais. Durante seu primeiro mandato (1995-1998), apoiado no sucesso do Plano Real, que interrompeu o processo inflacionário, Fernando Henrique Cardoso impôs aos governos estaduais medidas duras de ajuste fiscal que reduziram sua capacidade de influir na política nacional. Em seu segundo mandato, o impacto da crise internacional de 1998 e o enfraquecimento de sua grande coalizão congressual reduziram a capacidade do governo federal de coordenar o processo de reforma tributária e política iniciado em 1995.

Esta breve reconstrução da trajetória política da Federação brasileira ao longo do século XX aponta uma clara instabilidade na dinâmica institucional das relações intergovernamentais. Como argumentamos anteriormente, essa instabilidade está ancorada em duas características centrais do federalismo brasileiro: a capacidade da Presidência da República de controlar uma coalizão congressual ampla e estável o suficiente para neutralizar a influência de governadores e prefeitos sobre a política nacional; e o controle sobre o uso de recursos fiscais para a operação de um sistema de transferências condicionadas (denominadas no Brasil de "transferências voluntárias").

No período da chamada República Populista (1946-1964), o Estado desenvolvimentista dispunha de recursos suficientes para conduzir uma política de controle clientelista sobre estados e municípios, embora a capacidade de formação de coalizões estáveis tenha variado bastante em cada mandato presidencial. É importante notar que os períodos de instabilidade política estiveram associados ao enfraquecimento das coalizóes congressuais $(1954,1961,1964)$ e ao fortalecimento do papel político dos governadores em âmbito nacional.

Do mesmo modo, em todas as conjunturas críticas do processo de redemocratização, o enfraquecimento dos presidentes João Figueiredo 
Federalismo e relações intergovernamentais...

(1979-1984) e José Sarney (1985-1989) esteve associado ao fortalecimento político e fiscal dos governos subnacionais. Em contrapartida, a ampla descentralização fiscal imposta pelas forças regionais durante a Assembleia Nacional Constituinte (1987-1988) só foi revertida a partir de meados dos anos de 1990 pela recuperação da legitimidade do governo federal com a eleição de Fernando Henrique Cardoso (1995), sustentado pelo estrondoso sucesso do Plano Real (1994).

Quando analisamos todas as variáveis mencionadas nos parágrafos anteriores, somos levados a concluir que o Brasil constitui um caso extremo - pelo menos teoricamente - de predomínio dos interesses estaduais e municipais. Senão vejamos. O Senado brasileiro representa igualmente todos os estados-membros, tal como o Senado norte-americano e diferentemente da Câmara federal alemã (Bundesrat - Conselho federal). Neste caso, a representação é explicitamente federativa, pois os 16 governos regionais (Länder, equivalentes aos estados brasileiros) nomeiam entre três e seis delegados proporcionalmente à sua população. Assim, os representantes dos Länder, que podem ser membros do governo, atuam em bloco e seguem estritamente os interesses de seus governos. Segundo Alfred Stepan (1999), o grau de desproporcionalidade do Senado brasileiro é o maior entre todas as Câmaras territoriais, pois o número de senadores que representam $8 \%$ do eleitorado é maior que o dos senadores que representam os outros 90\%. Além disso, as atribuições legislativas do Senado são equivalentes às da Câmara dos Deputados. A composição da Câmara, por sua vez, também é fortemente desproporcional, já que os menores estados-membros elegem pelo menos 8 deputados, como é o caso de Roraima, e o maior - São Paulo - apenas 70 deputados. Para que se tenha ideia do que isso representa, uma estrita proporcionalidade significaria um deputado para Roraima contra 115 para São Paulo.

Finalmente, o Brasil parece combinar várias características: presidencialismo forte, com interferência direta no funcionamento do Poder Legislativo, sistema eleitoral proporcional com lista aberta e multipartidarismo, intensa participação da coalizão parlamentar na composição do governo (ministérios, secretarias, autarquias e empresas públicas) e forte presença de interesses regionais e estaduais no processo decisório, tanto no Poder Executivo como no Legislativo. Desse modo, o sistema oscila entre períodos de grande concentração de poder nas mãos da Presidência, especialmente durante os ciclos de crescimento econômico, e períodos de intensa descentralização, geralmente descoordenada, tanto 
do ponto de vista fiscal como político e administrativo. No entanto, em razão da grande desigualdade socioeconômica e fiscal entre as regióes e unidades federadas, mesmo nos períodos de descentralização, a União continua cumprindo um papel estratégico, pois a maioria dos estados e municípios depende fortemente de algum tipo de transferência de recursos para custear suas máquinas administrativas e financiar suas políticas públicas.

Contudo, como demonstrou Arretche (2000), a capacidade do governo federal de coordenar políticas e/ou induzir estados e municípios a assumir a execução de políticas públicas depende também da configuração própria de cada setor. Em setores nos quais ele teve historicamente um papel central na gestão e no financiamento, como no caso de saúde, saneamento e habitação, as políticas de descentralização teriam melhores perspectivas de sucesso porque o governo federal controlaria os recursos e instrumentos normativos e administrativos. Em outros, como ensino fundamental e médio, nos quais esse papel era secundário, a coordenação só poderia ser eficaz por meio de medidas legislativas gerais, como a Emenda Constitucional n. 14, que criou o FUNDEF.

O longo período de estabilidade institucional alcançado pelos governos de Fernando Henrique Cardoso (1995-2002) e Lula da Silva (2003-2010) teve um importante impacto na configuração das relações intergovernamentais. Apoiados, ambos, no sucesso do Plano Real e na capacidade de construir amplas (embora heterogêneas) bases de sustentação política no Congresso e na opinião pública, foram capazes de reconfigurar aspectos importantes das relaçôes intergovernamentais que fragilizaram os governos federais nas duas décadas anteriores.

No entanto, no campo das políticas sociais, o desempenho passado não permite uma avaliação simples. Em áreas como saúde, educação e assistência social houve avanços significativos, embora com impactos muito diferentes nas relações intergovernamentais (Arretche, 2000).

\section{Considerações finais}

Podemos concluir de tudo o que dissemos que o grande desafio atual da agenda federativa no Brasil tem sido, e será cada vez mais, a construção de mecanismos institucionais de coordenação que incluam estados e municípios não apenas na operação dessas políticas, mas, na 
Federalismo e relações intergovernamentais...

medida do possível, por meio do financiamento compartilhado. Neste sentido, algumas características específicas do nosso federalismo devem ser consideradas na formatação desse federalismo mais cooperativo.

O Brasil é uma das únicas federações com três esferas constitucionais de poder: federal, estadual e municipal. Isso coloca no centro da agenda a construção de mecanismos de coordenação/cooperação que incluam milhares de municípios bastante heterogêneos tanto do ponto de vista econômico-tributário como político e social. Parece evidente que esse processo tem de ser descentralizado e, mais do que isso, regionalizado. Neste sentido, podemos buscar inspiração no modelo do sus. Além de bastante descentralizado em suas operações básicas, o Sistema Único de Saúde também possui instâncias regionais de coordenação, as Comissões Bipartites, e caminha para a construção de sistemas regionalizados de gestão, com a incorporação gradual dos estados como agentes articuladores do sistema.

Em contrapartida, o país é extremamente heterogêneo, exigindo dos formuladores de mecanismos de cooperação e coordenação de políticas públicas muita sensibilidade para as diferentes necessidades e capacidades dos atores sociais. Em áreas como assistência social, não se pode pensar em modelos hierarquizados como o do sus, porque os problemas são muito diferentes em cada região. Nas áreas metropolitanas os problemas da violência, do crime organizado, associados ao desemprego industrial, cortam transversalmente os programas de assistência social para crianças e adolescentes. Nos municípios rurais, o problema central é o acesso aos bens e serviços públicos básicos, além de transferência de renda para famílias miseráveis. Já em áreas como saneamento e gestão de recursos hídricos, o impacto territorial das políticas é grande, exigindo estruturas mais complexas e com maior capacidade de coordenação horizontal, entre municípios e até estados, e vertical, envolvendo também a União.

Vejamos, finalmente, como a dinâmica das relações intergovernamentais afeta o campo das políticas educacionais.

Como argumenta Abrucio (2010), a dinâmica descentralizadora dos anos de 1980 mobilizou de forma intensa a heterogênea coalizão de forças favoráveis à reforma da educação no Brasil. Por sua vez, Araújo (2005), em sua tese de doutorado, demonstra um quadro heterogêneo, em que as forças favoráveis a uma descentralização radical com intensa 
participação popular entravam em conflito com posições mais preocupadas com os efeitos da descentralização, sem coordenação federativa sobre os padrões históricos de desigualdade e capacidade administrativa e financeira dos sistemas estaduais e municipais de educação.

A falta de coesão entre as forças sociais e políticas empenhadas na reforma da educação pública, em contraste com a forte articulação montada em torno da reforma da saúde - que resultou na criação do SUS -, explica em parte por que o movimento reformista não utilizou os instrumentos legais inscritos na Carta Constitucional de 1988 que estimulavam a construção de um Sistema Nacional de Educação. Segundo Abrucio (2010, p. 61):

A fragilidade do resultado se deveu à falta de um modelo intergovernamental que organizasse o processo de descentralização na educação. A municipalização ficou vinculada às negociações políticas entre os estados e municípios, sem que houvesse uma arena institucional para isso e/ou critérios claros de repasse de funções, de modo que este processo dependeu muito mais do jogo de poder federativo para além da política educacional em si. Dito de outro modo, não houve incentivos financeiros, gerenciais ou de democratização que guiassem a relação entre os níveis de governo e sua necessária colaboração.

É interessante ressaltar que isso aconteceu não obstante o único setor explicitamente subordinado ao "regime de colaboração" ter sido o da educação. Como demonstramos (Abrucio \& Costa, 1998, p. 150), a trajetória da reforma educacional, em contraste, outra vez, com a implantação do sus, foi contraditória. Por exemplo, entre 1980 e 1994, em pleno processo de regulamentação da Constituição, os estados continuaram expandindo sua participação nas matrículas no ensino fundamental, ao passo que as estruturas municipais reduziram seu espaço (idem, ibid.).

A reação dos governos federais às dificuldades de constituição de um efetivo "regime de colaboração" seguiu dois caminhos (Abrucio, 2010). Primeiro, a criação de um conjunto de programas e parâmetros nacionais que procuravam apoiar o desenvolvimento e reduzir as desigualdades, principalmente entre os sistemas municipais de educação. Embora relativamente bem-sucedidas, essas medidas de regulação e apoio tiveram impactos limitados. A segunda linha de ação, expressa pelo FUNDEF, objetivou uma mudança de impacto mais profundo na distribuição dos recursos financeiros entre sistemas estaduais e municipais. 
Federalismo e relações intergovernamentais...

Embora o FUNDEF e seu sucessor, o FUNDEB, tenham representado um passo importante para a criação das condições estruturais mínimas na direção de um Sistema Nacional de Educação, o caminho neste sentido ainda parece longo.

A estratégia de criação de fundos estaduais de equalização financeira foi inovadora e certamente teve um impacto relevante sobre as desigualdades gritantes no nível de gasto de sistemas estaduais e municipais de educação, e, principalmente, sobre a universalização das matrículas no ensino fundamental. No entanto, as limitações dessas iniciativas se tornam cada vez mais claras na medida em que os desafios no campo da educação vão além da eficiência do gasto.

Primeiro, ainda estamos longe de garantir um padrão mínimo de equalização inter-regional de gasto. Isso exigirá um papel mais robusto e incisivo do governo federal na redistribuição dos recursos fiscais, seja no sentido da formação de um Fundo Nacional e não apenas de um conjunto de fundos estaduais, como foi o FUNDEF e ainda é o FUNDEB. Em contrapartida, uma transformação efetiva na qualidade da educação pública impõe a construção de um sistema nacional (ou unificado) seguindo o exemplo do sUS, no qual a participação do governo federal terá de ser muito mais intensa. Dois exemplos.

Uma efetiva transformação da educação pública terá de passar por uma grande melhora no padrão de remuneração e qualificação, além da permanente capacitação, dos professores das redes estaduais e municipais. O governo federal, em colaboração com as redes estaduais e municipais, será obrigado a criar uma estrutura de coordenação bastante complexa para transformar o cenário desolador nesta área.

A transformação efetiva na área da educação também impõe uma mudança estrutural na organização dos sistemas de educação pública, especialmente no ensino fundamental. Para isso será preciso reduzir o nível de isolamento e fragmentação das redes municipais. Uma estratégia possível é a formação de consórcios regionais, a exemplo do que ocorre na área de saúde. Mas, para que isso aconteça, uma verdadeira revolução nas concepções predominantes na educação terá de acontecer. De novo, o papel do governo federal, com o apoio dos governos estaduais, seria fundamental.

Enfim, estes são apenas dois exemplos daquilo que denominamos ao longo do texto de coordenação e colaboração intergovernamental. 
Minha aposta é que um processo de nacionalização é fundamental para transformar a educação pública no Brasil. Mas isso só pode ocorrer como parte de uma estratégia política de construção de um regime democrático e federativo.

Recebido e aprovado em agosto de 2010.

\section{Referências}

ABRANCHES, S.H.H. Presidencialismo de coalizão: o dilema institucional brasileiro. Dados, Rio de Janeiro, v. 31, n. 1, p. 5-38, 1988.

ABRUCIO, F. Os baróes da Federação: governadores e a redemocratização brasileira. São Paulo: DCP; USP; HUCITEC, 2002.

ABRUCIO, F. A dinâmica federativa da educação brasileira: diagnóstico e propostas de aperfeiçoamento. In: Oliveira, R.P.; Santana, W. (Org.). Educação e federalismo no Brasil: combater as desigualdades, garantir a diversidade. Brasília, DF: UNESCO, 2010, p. 39-70.

ABRUCIO, F.; COSTA, V. Reforma do Estado e o contexto federativo brasileiro. São Paulo: Fundação Konrad Adenauer, 1998. (Série Pesquisa, 12)

ABRUCIO, F.; SAMUELS, D. A nova política dos governadores. Lua Nova, São Paulo, n. 40/41, p. 137-166, 1997.

ALMEIDA, M.H.T. Federalismo, democracia e governo no Brasil: ideias, hipóteses e evidências. Revista Brasileira de Informação Bibliográfica em Ciências Sociais, São Paulo, n. 51, p. 13-34, 2001.

ARAÚJO, G.C. Município, Federação e educação: história das instituições e das ideias políticas no Brasil. 2005. Tese (Doutorado) - Universidade de São Paulo, São Paulo.

ARAÚJO E OLIVEIRA, J.B. Avanços e impasses na educação: à guisa de balanço. Revista do Legislativo, Belo Horizonte, n. 21, p. 16-27, jan./ mar. 1998.

ARRETCHE, M. Estado federativo e politicas sociais: determinantes da descentralização. Rio de Janeiro: Revan/FAPESP, 2000. 
COSTA, V. Brazil. In: Griffiths, A.; Nerenberg, K. (Org.). Handbook of federal countries 2005. 2 ed. Montreal: McGill-Queen's University, 2005. v. 1, p. 90-106.

CURY, C.R.J. Sistema Nacional de Educação: desafio para uma educação igualitária e federativa. Educação \& Sociedade, Campinas, v. 19, n. 105, p. 1187-1209, set./dez. 2008.

KING, P. Federalism and federation. Baltimore: John Hopkins University, 1982.

KUGELMAS, E.; SOLA, L. Recentralização/descentralização: dinâmica do regime federativo no Brasil dos anos 90. Tempo Social, São Paulo, v. 11, n. 2, p. 63-83, 1999.

LIMONGI, F.; FIGUEIREDO, A.C. Bases institucionais do presidencialismo de coalizão. Lua Nova, São Paulo, n. 44, p. 81-106, 1998.

NICOLAU, J.M. As distorções na representação dos estados na Câmara dos Deputados brasileira. Dados, Rio de Janeiro, v. 40, n. 3, p. 441-464, 1997.

STEPAN, A. Para uma nova análise comparativa do federalismo e da democracia: federaçóes que restringem e ampliam o poder do demos. Dados, Rio de Janeiro, v. 42, n. 2, p. 197-252, 1999. 